\title{
Synergic Swelling of Interactive Network Support and Block Copolymer Films during Solvent Vapor Annealing
}

\author{
Wojciech Ogieglo, ${ }^{\dagger, \perp}$ Anja Stenbock-Fermor, ${ }^{\dagger}$ Thomas M. Juraschek, ${ }^{\dagger}, \#$ Yulia Bogdanova, ${ }^{\S}$ \\ Nieck Benes, ${ }^{\ddagger}$ and Larisa A. Tsarkova ${ }^{*, \$,},{ }_{\odot}$ \\ ${ }^{\dagger}$ DWI-Leibniz-Institut für Interaktive Materialien, Forckenbeckstraße 50, 52056 Aachen, Germany \\ ${ }^{\ddagger}$ Membrane Science and Technology Cluster/Films in Fluids Group, Faculty of Science and Technology, University of Twente, \\ 7500 AE Enschede, The Netherlands \\ ${ }^{\S}$ Chair of Colloid Chemistry, Faculty of Chemistry, Moscow State University, 1-3 Leninskiye Gory, 119991 Moscow, Russia \\ "Deutsches Textilforschungszentrum Nord-West gGmbH (DTNW), Adlerstraße 1, 47798 Krefeld, Germany
}

Supporting Information

\begin{abstract}
We report the effect of "interactive" polymer network (PN) supports on the solvent-vapor processing of thin polymer films. Densely cross-linked surface-attached network exhibits under experimental time scale a glassy swelling behavior with the conformational states and solventuptake clearly sensitive to the degree of solvent vapor saturation in the atmosphere. Pretreatment of the thermally cured PN films by complete immersion or by swelling in saturated chloroform vapors facilitates relaxation of the residual stresses and induces irreversible changes to the network structure as revealed by the swelling/deswelling tests. The presence of a polymer film on top of the PN support results in a mutual influence of the layers on the respective swelling kinetics, steady-state solvent uptake, and chain dynamics. Using UV-vis ellipsometry, we revealed a significantly faster swelling and higher solvent uptake of glassy PN layer below a polymer film as compared to a single PN layer on silicon substrate. Remarkably, the swelling of the network support continues to increase even when the overall swelling of the bilayer is in a steady-state regime. Block copolymer films on PN supports exhibit a faster ordering dynamics and exceptional stability toward dewetting as compared to similar films on silicon wafers. The mechanical stress produced by continuously swelling PN is suggested to account for the enhanced segmental dynamics even at low solvent concentration in the block copolymer film. Apart from novel insights into dynamics of solvent uptake by heterogeneous polymer films, these results might be useful in developing novel approaches toward fast-processing/annealing of functional polymer films and fibers.
\end{abstract}

\section{INTRODUCTION}

Processing and properties of polymer films are of increasing importance in a view of their numerous technological applications as functional coatings, membranes, sensors, and in microelectronic and optical devices. Particularly, an extensive reserach of the last decades on block copolymers has been stimulated by their ability to assemble in thin films into chemical and topographic patterns with the dimensions in the range from sub $10 \mathrm{~nm}$ up to tens of nanometers. ${ }^{1}$ Current trends to miniaturize devices dictate specific requirements for low-cost efficient manufacturing, as well as for high standards of reproducibility, homogeneity, and stability of processed polymer films.

Polymers possess a high conformational entropy introduced by monomer connectivity, so that the behavior and properties of polymer films are tremendously affected by the proximity to a solid interface and to a free surface. ${ }^{2-4}$ Extensive research has revealed that physical properties of glassy polymer films with the thickness on the order of or below the radius of gyration of the polymer, $R_{g}$, differ substantially from their bulk values. Along with such parameters as glass transition temperature $T_{g}$, local chain mobility, ${ }^{2,5-8}$ flow and intermolecular entanglements, $^{9-11}$ thermal contraction or expansion, ${ }^{12}$ also solvent sorption and swelling dynamics ${ }^{13-16}$ are largely sensitive to the confinement and to the vicinity of the polymer chains to the (thermal) equilibrium state, that is, to the degree of annealing. ${ }^{4}$

The functional applications of polymer films as sensors, ${ }^{17-19}$ membranes, ${ }^{20}$ and coatings ${ }^{18,21,22}$ to a great extent guide the research on solvent uptake by polymer films, including mechanisms of solvent permeation and swelling dynamics. Earlier studies on the swelling behavior of functional coatings have addressed films comprising polymer materials with different molecular architectures ranging from glassy polymer

Received: July 9, 2018

Published: August 2, 2018 
films, ${ }^{23-25}$ organic networks, ${ }^{26,27}$ or hydrogels ${ }^{28,29}$ to environmentally responsive molecular brushes ${ }^{30-32}$ and nanostructured block copolymer films. ${ }^{33-35}$ Studies on the swelling behavior of cross-linked polymer films have been focused on relating uniaxial deformation expected from rubber elasticity theories to the experimentally measured swelling data. ${ }^{36,37}$ They provide valuable information regarding network properties under confinement. ${ }^{38}$ In particular, the swelling/deswelling kinetics of polymeric networks, relevant for drug release applications or to filtration membranes, can be correlated with the cross-linking density, ${ }^{23}$ that is, with the mesh size of a network. $^{21}$

Another issue which has been intensively studied in last decades relates to solvent vapor annealing when small solvent molecules act as plasticizers by reducing the effective $T_{\mathrm{g}}$ down to or below room temperature, or they increase the crystallization temperature and therefore provide relaxation of frozen-in nonequilibrium conformational states induced by spin-coating or roll-to-roll preparation procedures. Major efforts in this research direction have been focused on the improvement of the pattern characteristics of nanostructures formed by block copolymers. ${ }^{39,40}$ Besides potential applications in block copolymer-assisted lithography, solvent vapor annealing was shown to affect the structural development of crystalline functional polymers and hence to advance the performance of designed polymer solar cells and electronic devices. ${ }^{41-43}$

A negative aspect of the enhanced chain mobility in the presence of the solvent molecules is the reduction of the interactions with the substrate and, accordingly, an increased risk of the film rupture because of dewetting. The concepts toward inhibition of dewetting thin polymer films commonly involve the modification of the substrate or of the polymer to influence the interfacial tension, ${ }^{44-47}$ as well as the reduction of the mobility of the polymer chains as a result of crosslinking $^{48}$ or interlocking with surface-immobilized network layers ${ }^{49}$ or with single polymer chains. ${ }^{50-52}$ In particular, Jeon et al. ${ }^{49}$ have demonstrated a retardation of dewetting of thermally annealed polystyrene (PS) films supported by epoxy network layers.

Previously, ${ }^{53}$ we have reported that highly cross-linked polymer network (PN) supports provide at least a 10-fold enhancement of the microdomain ordering dynamics of block copolymer nanostructures with different structural and chemical composition. This effect was very pronounced at a low-solvent concentration in the film, that is, when the segregation regime is in the range from intermediate to strong. Also, we have concluded that the similarity of the phase behavior in solvent-annealed block copolymer films on PN supports and on silicon substrates is due to the screening effect of the solvent. Another practically valuable reported effect of the PN support is a suppression of dewetting of polymer films during solvent vapor processing, although the underlying mechanisms remained unrevealed.

The organic cross-linked materials used in this study are increasingly used in nanofabrication as lithographic or etching masks for the production of topographically structured surfaces, patterns for templates, and components for microelectronic devices. ${ }^{54}$ With regard to the processing of block copolymer films, highly permeable networks on top of the films have been demonstrated to yield a significant improvement of the microdomain ordering during solvent vapor annealing. ${ }^{55-58}$ More generally, utilization of soft interfaces, which may exhibit complex behavior in response to solvent vapor environment, is envisaged to affect the dynamic properties and functioning of thin polymer films. ${ }^{59}$

In this paper, we focus on the behavior of "interactive" network layer which conformational state and respective solvent uptake are sensitive to the environmental conditions. We compare the annealing behavior of individual PN layer and of bilayer systems consisting of PS, poly(methyl methacrylate) (PMMA) homopolymers, and polystyrene- $b$-polybutadiene (PS- $b$-PB) block copolymer films atop the PN support. Swelling experiments have been performed in an annealing setup which allows for high levels of control over the vapor saturation, flow, and temperature. ${ }^{14,53,60-62}$ The paper is organized as the following. We first present the results on solvent treatment of individual thermally cured $\mathrm{PN}$ films via complete immersion or via swelling in solvent vapors. The respective irreversible changes to the conformation of the network are reflected in the measured swelling/deswelling behavior. Next, we present kinetics and steady-state solvent uptake by individual thermally cured network layers with varied degrees of the residual stresses. The comparison of the structure development in cylinder-forming PS- $b$-PB block copolymer films on PN supports and on silicon wafers is used to conclude on enhanced segmental dynamics of linear polymer chains in contact with a swelling substrate. Further, using in situ UV-vis ellipsometry, we resolve individual swelling of the PN and PS- $b$-PB layers in the bilayer systems and evaluate mutual effects of the layers on the kinetics of swelling, steady-state solvent uptake, and chain dynamics. Finally, we demonstrate a high stability against dewetting of homopolymers films on PN supports for a wide range of polymer molecular weights and for different chemical compositions.

\section{EXPERIMENTAL SECTION}

Polymer Samples. PS $(5.6,30,178 \mathrm{~kg} / \mathrm{mol})$, polymethylmethacrylate $(34 \mathrm{~kg} / \mathrm{mol})$, and poly(styrene- $b$-butadiene) diblock copolymer (denoted as PS- $b$-PB) were purchased from Polymer Source Inc. and used as received. PS- $b$-PB has a total molecular weight of $M_{n}=$ $47.3 \mathrm{~kg} / \mathrm{mol}$ and a polydispersity index of 1.03 . The volume fraction of the PS block (26.1\%) results in bulk morphology of hexagonally ordered PS cylinders with a characteristic spacing $\mathrm{d}_{0}$ of $32.9 \pm 0.3 \mathrm{~nm}$ and interlayer spacing of $\sim 27 \mathrm{~nm}\left(3 \sqrt{2} \mathrm{~d}_{0}\right) .{ }^{63}$ To stabilize the PB against cross-linking during film processing, a stabilizer (2,6-di-tertbutyl-p-cresol) was added to solutions in the amount of $0.03 \%$ of the polymer weight.

Substrates. Polished silicon wafers (CrysTec) were cut in $0.5-1$ $\mathrm{cm}^{2}$ pieces and cleaned via ultrasonication in toluene for $10 \mathrm{~min}$ to remove organic residues. Directly before use, the substrates were cleaned with $\mathrm{CO}_{2}$ snow jetting and then with air-plasma for $1 \mathrm{~min}$ at 0.2 mbar.

Network supports have been prepared by spin-coating the solution (HM8006-8 as purchased from JSR Micro) at $5000 \mathrm{rpm}^{54}$ The coatings were then cured on a hot plate at $225^{\circ} \mathrm{C}$ for $90 \mathrm{~s}$, resulting in a densely cross-linked network films.

Film Preparation. Homopolymer films and PS- $b$-PB films were prepared from fresh, filtered solutions in toluene (VWR) via spincoating onto silicon substrates or network supports. The concentration of polymer solutions $(0.25-1 \mathrm{wt} \%)$ and spinning rates (2000-3000 rpm) have been chosen to achieve desired film thicknesses which has been measured with ellipsometry (Omt Imaging ellipsometer). In the case of polymer-network bilayer films, the thickness of the homopolymer or block copolymer films was evaluated by subtracting the starting network-coating thickness from the total bilayer thickness. When similar casting conditions have been used, the deviations in film thickness on silicon wafers and on network 
support were comparable with typical thickness deviations upon spincoating procedure. The films have been dried overnight in a vacuum oven prior to the measurements.

Solvent Vapor Annealing. Solvent vapor annealing of polymer films has been performed in a custom-made steel chamber with a thermostated tubing for maintaining constant temperatures of vapor and of the substrate and quartz windows allowing for in situ ellipsometry measurements of the swollen film thickness $h_{\mathrm{sw}}{ }^{53}$ Dry nitrogen and solvent vapor flows are directed through a channel system made of Swagelok components. The partial vapor pressure $p /$ $p_{0}$ of chloroform inside the chamber was adjusted by mixing controlled flows (Brooks Instrument flow controllers) of pure nitrogen with a flow of carrier gas (nitrogen) purged through a thermostated vial with chloroform. We note that the values of $p / p_{0}$ evaluated in this study are higher than the actual vapor pressure in the chamber because of the flow conditions. An exact way is to measure the partial pressure of solvent at each ratio using, for example, mass spectrometry at the chamber outlet, as was properly performed by Shelton et al. ${ }^{64}$

The stability of the processing conditions was monitored via measurements of the swollen films thickness $h_{\mathrm{sw}}$. The polymer volume fraction in a swollen film is estimated as: $\phi=h_{\mathrm{dr}} / h_{\mathrm{sw}}$, where $h_{\mathrm{dr}}$ is the thickness of the as-spin-coated and dried films. Standard annealing settings have been used in all experiments: a total flow of $100 \mathrm{sccm}$, solvent vapor temperature of $20.0^{\circ} \mathrm{C}$, and a substrate temperature of $21.0^{\circ} \mathrm{C}$. All films were quenched inside the chamber by a $100 \mathrm{sccm}$ nitrogen flow for $10 \mathrm{~min}$ before removing the samples.

In situ vis-ellipsometry measurements have been performed with imaging ellipsometer (Omt, $\mathrm{mm} 30$ series) at $70^{\circ}$ incidence angle in a spectral range of $450-800 \mathrm{~nm}$ using software VisuEl 3.8. Analysis was made through fitting by Scout Software using a Cauchy model, where block copolymer films and hard mask layers are modeled as a homogeneous material.

UV-ellipsometer (J. A. Woollam M-2000X) has been used to resolve the swelling of individual layers in network-PS- $b$-PB bilayer films using a slightly different annealing setup. The sample was initially stabilized in a dry nitrogen flow. Then, a saturated chloroform vapor, equilibrated in a reservoir with the solvent at a certain temperature, was purged through the stainless steel cell with quartz windows with the sample, and the film thickness was monitored in time. The resulting partial vapor pressure $p / p_{0}$ was evaluated according to the temperature dependence of the saturated vapor pressure of the chloroform (Table S1, Supporting Information).

Structure Characterization. The as-spin-coated and annealed block copolymer/homopolymer films have been characterized with optical microscopy (Keyence, VHX2000) for macroscopic surface structures. Microphase separation behavior in block copolymer films has been analyzed by a Bruker Dimension Icon scanning force microscope in TM using Nanoscope 8.10 software and OTESPA tips (spring constant, 12-103 N/m and resonant frequency, 278-357 $\mathrm{kHz}$ ) under ambient conditions.

Wetting Measurements. Quasi-equilibrium contact angles of probe liquids (bidistilled water and diiodomethane $\mathrm{CH}_{2} \mathrm{I}_{2}$ ) at advancing and receding conditions have been measured with sessile drop or captive bubble techniques using a horizontal microscope ( $\times 25$ magnification) with a goniometer. Contact angle values were captured within $30 \mathrm{~s}$ of droplet/bubble contact with the surface, before the volume of the droplets started to decrease as a result of the penetration of liquid into the network to assure the advancing angle conditions. Receding conditions were created by the formation of adhering air bubble to the surface of the tested sample immersed in water. The volumes of the droplets/bubbles were ca. $10 \mu \mathrm{L}$. For each substrate, five to seven droplets/bubbles have been measured.

Surface energy values including their polar $\gamma_{\mathrm{p}}$ and dispersive $\gamma_{\mathrm{p}}$ modes (components) were calculated according to Owens-Wendt model. ${ }^{65}$ Briefly, this method is based on the solution of a system of equations with the known values of $\gamma_{\mathrm{p}}$ and $\gamma_{\mathrm{p}}$ of the test liquids.

\section{RESULTS AND DISCUSSION}

The cross-linked PN material utilized in the present study is a commercial organic hard mask designed for lithographic fabrications. ${ }^{54} \mathrm{~A}$ fully cured network material has a weak $T_{\mathrm{g}}$ around $280{ }^{\circ} \mathrm{C}$ (Figure S1, Supporting Information), as established by thermal ellipsometric dilatometric measurements. In the range above $200{ }^{\circ} \mathrm{C}$, the network film has been found to start degrading, as evidenced by an increase of optical absorption in the UV range (Figure S2, Supporting Information). Such an increase of light absorption is often found during the formation of conjugated aromatic structures related to the chemical alteration. The evident glassy character of the network is confirmed by the appearance of thickness relaxation during annealing, representing physical aging. The physical aging only occurs in nonequilibrium glasses and is correlated with a collapse of the excess fractional-free volume present in the frozen-in structure of the glass. In the following, we describe the solvent vapor uptake by network films, both as individual layers and as supports for polymer films.

Effect of the Solvent Treatment on the Swelling Behavior of Densely Cross-Linked PN. Network films with a thickness in a dry state of $\sim 60 \mathrm{~nm}$ have been exposed to a controlled atmosphere of chloroform vapors. The swelling kinetics and the degree of swelling of the as-cured networks (sketch A in Figure 1) have been compared with that of pretreated PNs: cross-linked network after immersion in

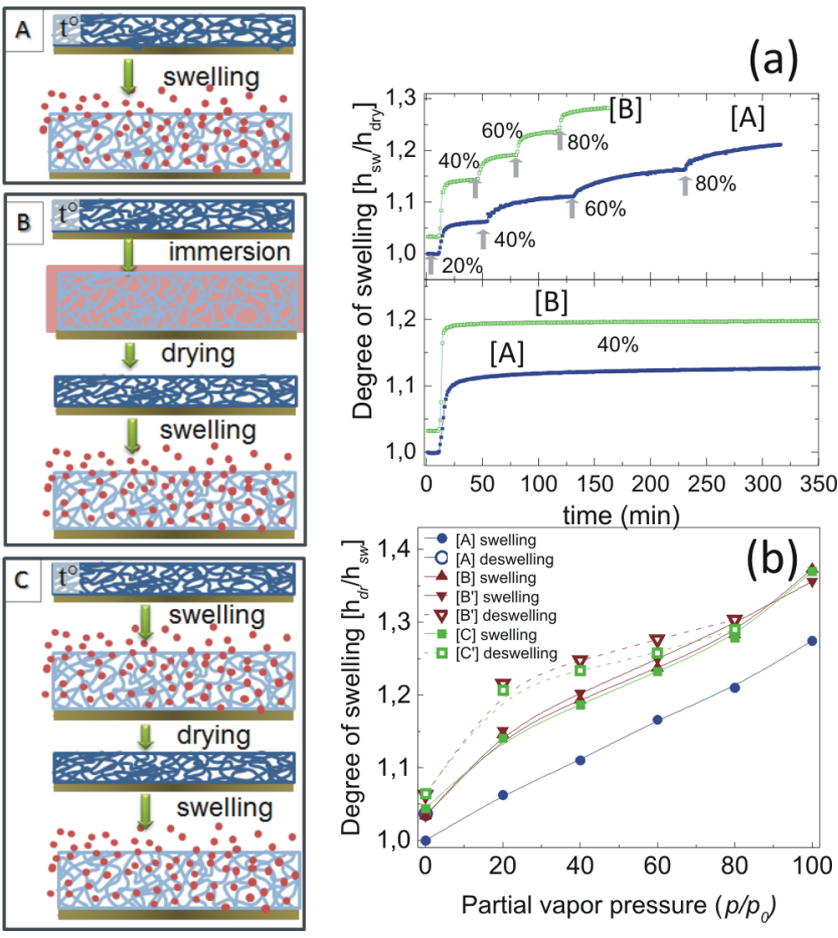

Figure 1. Sketches (A-C) illustrate the treatment steps applied to PN films on silicon wafers. (a) Degree of swelling of PN films [A] and [B] (as in respective sketches) vs time (top plot) upon stepwise increase of the partial vapor pressure of chloroform $p / p_{0}$ as indicated to 20,40 , 60 , and $80 \%$ and (bottom plot) of similar network films continuously swollen at $p / p_{0}$ of $40 \%$. (b) Degree of swelling (solid lines) of PN layers vs chloroform vapor $p / p_{0}$ : blue circles-as cured network [A]; lilac triangles-immersed in chloroform for $2 \mathrm{~h}$ and for $24 \mathrm{~h}\left[\mathrm{~B}, \mathrm{~B}^{\prime}\right]$, respectively; green squares-second swollen cycle of preswollen vapors and dried PN [C]. Deswelling curves are shown for pretreated networks (empty symbols, dashed lines) as indicated. 
chloroform for several hours and subsequent drying (sketch B in Figure 1) and densely cross-linked network which underwent a swelling/deswelling cycle in 100\% saturated chloroform vapors (sketch $\mathrm{C}$ in Figure 1).

Shown in Figure 1a are the results of in situ vis-ellipsometric measurements expressed as a degree of swelling (a ratio of dry to swollen film thickness $h_{\mathrm{dry}} / h_{\mathrm{sw}}$ ) versus time upon stepwise exposure of the films to temperature-controlled environment with indicated values of the partial vapor pressure $p / p_{0}$ of chloroform. We note that the starting swelling factor of pretreated networks is normalized by the thickness of the ascured network. Its slightly above unity value is due to richer excess free volume of predilated structures ${ }^{20}$ or due to the presence of the residual solvent leading to a preswollen starting state. ${ }^{66}$ The swelling curve of the as-cured network demonstrates a glassy swelling behavior, that is, a continuous slow increase in swelling even after several hours (curve [A], bottom graph of Figure 1a) and a low degree of swelling of $\sim 1.2$ even at high vapor saturations (curve [A], upper graph). Upon solvent pretreatment, the swelling curves [B] show a faster kinetics and a higher solvent uptake, which reaches a steady-state within ca. $20 \mathrm{~min}$. The changes in the swelling behavior upon pretreatment with a solvent are attributed to the relaxations of the network junctions and of residual stresses in the cured films.

The swelling/deswelling curves are presented in Figure S3 (Supporting Information), and Figure $1 \mathrm{~b}$ summarizes the degree of swelling/deswelling versus partial vapor pressure $p$ / $p_{0}$ for the studied samples. For the as-cured network [A], the asymptotic values at each swelling step are plotted. All pretreated networks show similar values of the solvent uptake, irrespective of the solvent pretreatment procedure. At a reduced solvent vapor atmosphere of $20 \% p / p_{0}$, the pretreated network films swell $\sim 2.2$ times more than the as-cured ones; the difference in the swelling drops down to $\sim 1.2$ with an increasing solvent concentration in the chamber. The step from 0 to $20 \% p / p_{0}$ of the swelling isotherms of the pretreated networks shows a slightly increased degree of swelling as compared to the as-cured network, resembling a Langmuir-like sorption mode of the so-called dual-mode sorption model. ${ }^{67}$

Deswelling isotherms of pretreated networks in Figure $1 \mathrm{~b}$ reveal a strong hysteresis, especially at a reduced solvent vapor atmosphere with the deswelling curves lying significantly above the swelling curves. This is a typical effect for glassy polymers, where the rigid network is kinetically trapped upon removal of solvent in an out-of-equilibrium, predilated state. The results in Figure $1 \mathrm{~b}$ demonstrate that solvent pretreatment, both by immersion in solvent and by swelling/drying step, induces irreversible changes to the conformation of cured network structure, so that its swelling behavior clearly changes upon the pretreatment procedure, even when the solvent fraction in the swollen network during processing is as low as $\sim 0.2-0.3$.

The analysis of the contact angle measurements on polished silicon wafers and on PNs, as cured and pretreated in chloroform, is presented in Figure S5 (Supporting Information). Advancing contact angles insignificantly differ for three types of studied samples. In contrast, the values of the receding contact angles are significantly lower for the PN films, indicating a hysteresis of $\Delta \theta \approx 30^{\circ}$ (Table S2, Supporting Information).

SFM images of the as-cured network reveal a homogeneous smooth surface (Figure S4, Supporting Information). The surface roughness changes insignificantly upon immersion in solvent [B] or swelling/deswelling cycle [C]. Small globular features which appear at the surface upon the latter treatment may represent noncross-linked residues or collapsed dangling ends of grafted chains.

The results in Figure 1 provide new insights to Schroeder's paradox ${ }^{68}$ which states that the swelling of polymeric networks in liquids is always higher than in the corresponding saturated vapors. The general nature of this phenomenon is explained by the fact that the absolute activity of any sorbate in its liquid form is always larger than in the form of its saturated vapor. Earlier study on the swelling of cross-linked polymeric beads led to another possible explanation of Schroeder's paradox. ${ }^{69}$ The authors found that strain-relaxed gels with any solvent contents retain their volumes constant in the saturated vapor atmosphere, and they attributed this effect to the specificity of the polymer-solvent interactions in network polymers. Our results in Figure 1 additionally indicate that comparison of solvent immersion and solvent sorption/desorption conditions should account for drastically different equilibration times, and that the long-term contact of PNs with saturated solvent vapors is as efficient in releasing the stresses and unfavorable conformations as immersion in solvents.

Swelling Behavior of Networks with Varied CrossLinked Densities. To study the effect of the cross-linking density on the swelling behavior of PNs, we produced films with varied degree of cross-linking by employing different curing temperatures, as indicated in Figure 2. Curing

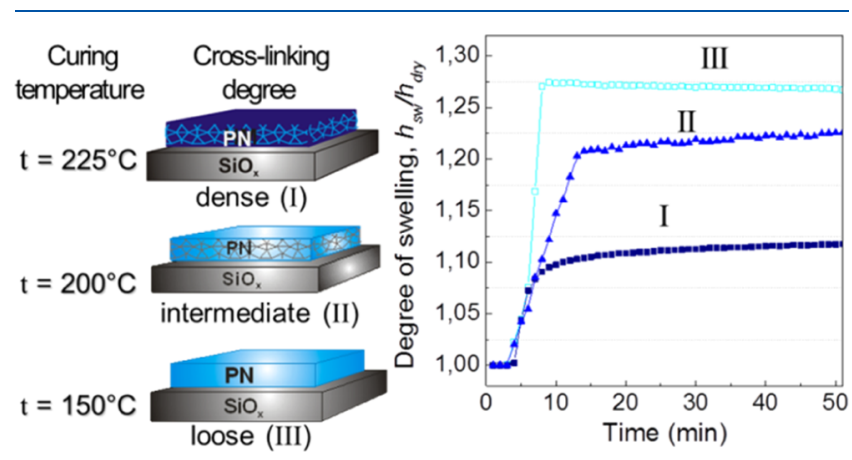

Figure 2. Kinetic plots of the degree of swelling of network layers exposed to the atmosphere containing $40 \% p / p_{0}$ of chloroform: (I), filled squares-curing temperature $225^{\circ} \mathrm{C}, h_{\text {dry }} \approx 54 \mathrm{~nm}$; (II), filled triangles $-200{ }^{\circ} \mathrm{C}, h_{\mathrm{dry}} \approx 130 \mathrm{~nm}$; and (III), empty squares $-150{ }^{\circ} \mathrm{C}$, $h_{\mathrm{dry}} \approx 60 \mathrm{~nm}$.

temperatures have been adapted to obtain (I) densely crosslinked state $\left(T_{c}=225{ }^{\circ} \mathrm{C}\right)$, (II) intermediately cross-linked state $\left(T_{\mathrm{c}}=200{ }^{\circ} \mathrm{C}\right)$, and (III) loosely cross-linked state $\left(T_{\mathrm{c}}=\right.$ $150{ }^{\circ} \mathrm{C}$ ) of the network (schematics in Figure 2). An altered degree of cross-linking is expected to lead to differences in mesh size and accordingly in the swelling behavior of the network. $^{28}$

Shown in Figure 2 is the swelling kinetics of each network film exposed to $40 \% p / p_{0}$ of the chloroform. The kinetics of the solvent uptake within the first 3-4 min of swelling are similar for all three networks, indicating similar diffusion rates of the solvent molecules through the top molecular layers of the film. At longer times, the slopes of the swelling curves are clearly dependent on the degree of cross-linking density. The densely cross-linked network (I) swells up to a degree of $\sim 1.1$ with the slope of the swelling curve not leveling off even after $50 \mathrm{~min}$ of annealing. The type of the swelling suggests a 


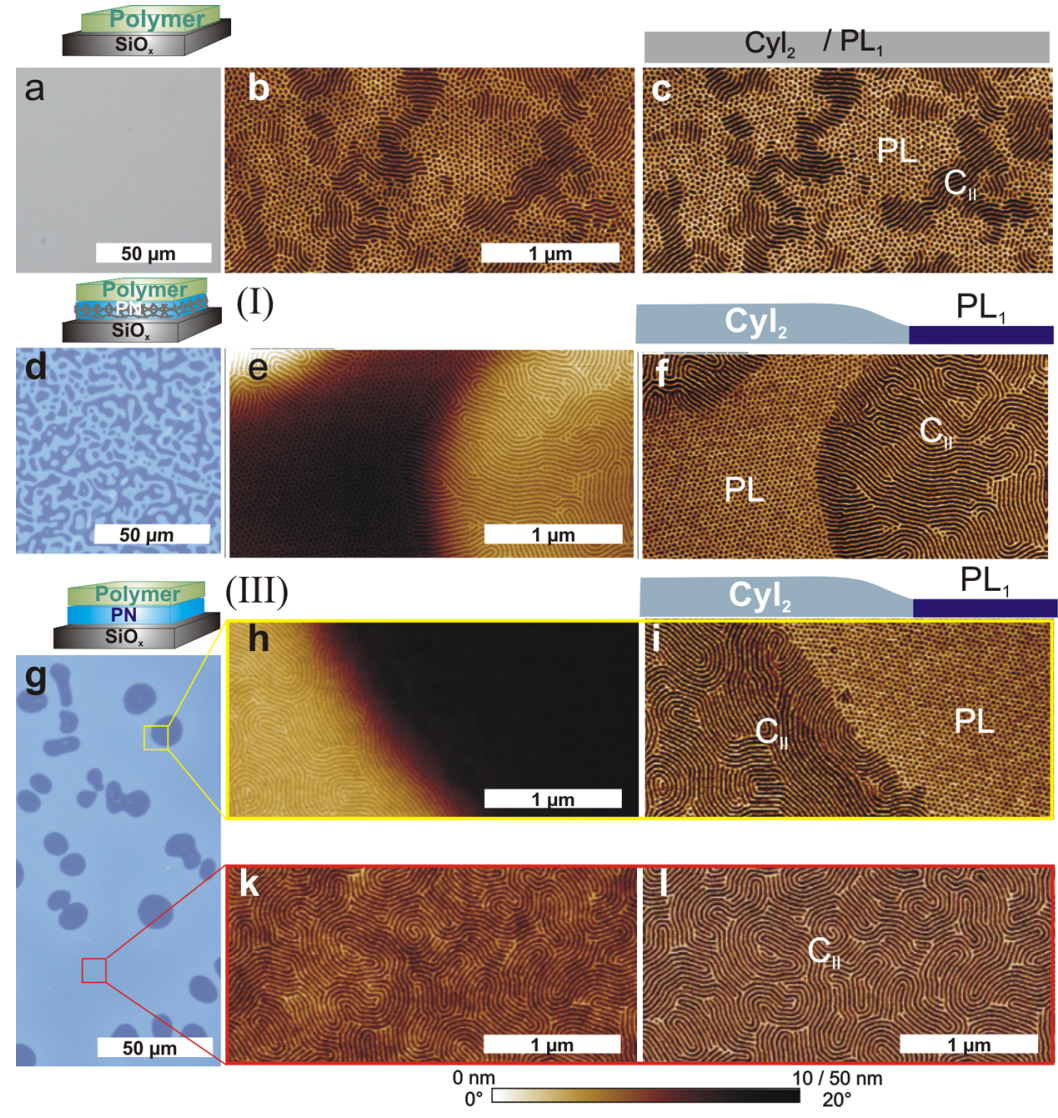

Figure 3. (a-c) Optical microscopy images (left column) and corresponding SFM topography (middle column) and phase (right column) images of PS- $b$-PB films with an averaged thickness of $\sim 50 \mathrm{~nm}$ annealed simultaneously under $50 \% \mathrm{p} / \mathrm{p}_{0}$ of chloroform for $1 \mathrm{~h}$ at controlled temperature conditions (solvent vapor temperature $20.0^{\circ} \mathrm{C}$, the substrate temperature $21.0^{\circ} \mathrm{C}$ ). Polymer volume fraction $\left(h_{\mathrm{sw}} / h_{\mathrm{dry}}\right)$ measured in situ on silicon substrate was 0.8 . PS- $b$-PB films were spin-coated onto $(a-c)$ silicon substrates, $(d-f)$ densely cross-linked network, (I) and (g-l) loosely crosslinked network layer (III). The colored squares in ( $\mathrm{g}$ ) indicate the position of the corresponding zoom-in SFM images. The sketches above the phase images assign the morphologies to the film topography: perforated lamella (PL) in lower terrace and in-plane cylinder phase $\mathrm{C}_{\|}$in the upper terrace. The scale in topography images $(\mathrm{b}, \mathrm{k})$ and $(\mathrm{e}, \mathrm{h})$ is 10 and $50 \mathrm{~nm}$, respectively.

combined Fickian-relaxational behavior, ${ }^{70}$ indicated by a rather slow, relaxation-driven equilibration between 5 and $30 \mathrm{~min}$. Presumably, in this case, the swelling does not induce the glass transition. ${ }^{23}$ Intermediately cross-linked network (II) achieves a higher degree of swelling $(>1.2)$ which is similar to that for solvent-treated network in Figure 1a. The linear dependence of the swelling on time (up to $10 \mathrm{~min}$ ) is characteristic of the socalled anomalous case II diffusion with a sharp penetrant front moving through the swelling film. The front velocity in this case depends on the polymer chain relaxation rate at the front and not on the diffusion of the small-penetrant molecules. This suggests that the swollen network II is in a close vicinity to its glass transition.

The ellipsometric data gained for loosely cross-linked network III indicates a fast swelling and a saturation achieved already within $10 \mathrm{~min}$. The swelling degree at the steady state is $\sim 1.27$ which is about 2.3 times larger as compared to the densely cross-linked network. Fast swelling is typical to rubbery polymers (e.g., polydimethylsiloxane in good solvents), thus indicating full plasticization or induction of glass transition in the network film. We note that this layer can be removed by washing with chloroform because of a loose adhesion to the substrate. The deswelling of the network (III) is faster relative to the network with higher cross-linking density and has a similar slope as the swelling curve (Figure S6, Supporting Information).
Results in Figure 2 demonstrate that the degree of network cross-linking affects the penetrant diffusion mechanisms. This observation provides indirect information on the glasstransition temperature of the cross-linked film. Furthermore, geometric constraints in the bulk of dense networks, as well as irreversible binding of the chains to the substrate restrict the extension of network chains in the direction normal to the surface. ${ }^{37}$ It is remarkable and practically important that such a spectrum of swelling dynamics can result from a simple adjustment of the curing temperature which affects the crosslinking density.

In the following, we address the effect of the swelling support on the equilibration of block copolymer films.

Morphological Behavior of Block Copolymer Films. The methodology to compare block copolymer chain dynamics on different substrates is based on the analysis of the structure development on meso- and nanoscales. In contrast to the films of homopolymers, the visualization of the evolved translational and morphological order of microdomains allows deriving direct conclusions on the efficiency of the annealing, that is, on the closeness of the system to the thermodynamic equilibrium, as well as on the chain conformations. At the same time, spontaneous roughening of the free surface (macroscopic terrace formation) of thin block copolymer films ${ }^{71,72}$ can be followed in time as a measure of the chain dynamics ${ }^{53,61}$ or even as a measure of the interfacial 
interactions with the substrate. ${ }^{73,74}$ Furthermore, high sensitivity of the microphase separation to the concentration of the solvent in a swollen film allows assessment of the reproducibility of the annealing conditions.

Films of PS- $b$-PB block copolymer with a thickness of $\sim 50$ $\mathrm{nm}(\sim 1.7$ domain spacing) have been spin-coated on silicon substrates and on network supports and annealed simultaneously under temperature and flow-controlled solvent vapor atmosphere to avoid the influence of small environmental instabilities on the comparative experiment. Figure 3 presents optical images and SFM images of the surfaces of PS- $b$-PB films spin-coated and processed in $50 \% \mathrm{p} / \mathrm{p}_{0}$ of chloroform for $1 \mathrm{~h}$ onto silicon substrates and on network supports. We note that the microphase-separated pattern after spin-coating looks very similar for both substrates indicating no noticeable effect of a possible solvent retention by $\mathrm{PN}$ during spin-coating (Figure S7, Supporting Information).

The film on silicon substrate (upper panel in Figure 1) has a smooth surface upon annealing. On the nanoscale, SFM topography and phase images reveal a pattern of coexisting dark dots (PL phase) and stripes (in-plane cylinder morphology), in agreement with earlier studies on solvent vapor annealing of this block copolymer. ${ }^{75-77}$

Films supported by network layers (Figure 3d-1) form terraces with equilibrium film thicknesses, as seen from the two distinct colors in the optical microscopy images. On the nanoscale, the same morphologies as were seen on silicon substrates appear at particular film thickness: PL in the lower terrace with one layer of structures and cylinder phase-in the higher areas with two layers of structures. From earlier studies of PS- $b$-PB films on silicon wafers, we know that the spatial segregation of the PL and cylindrical phase as in Figure $3 \mathrm{e}-\mathrm{i}$ is achieved on a 10 -fold longer time scale of annealing. ${ }^{53}$ In this earlier study, we concluded that increased solvent uptake by block copolymer film on a swollen network support cannot account for the observed enhanced segmental dynamic as compared to similar block copolymer films on silicon substrate. In case of a dilution of the concentrated polymer solution by ca. $5 \%$, the morphology in the film would have been changed from the coexisting PL/cylinder phase to the pure cylinder phase (Figure S8, Supporting Information), which was not the case. We note that the observed morphological behavior indicates that the symmetric wetting conditions are preserved on both substrates, so that the PB block segregates both to the substrate and to the free surface of the film. ${ }^{63}$

The structures in Figure $3 \mathrm{f}$ and in Figure $3 \mathrm{i}$ do not show principle differences neither in terms of the developed morphology nor in the degree of long-range-order of cylindrical and of PL domains. Therefore, at this stage of research, we could not establish the effects of the degree of cross-linking of the support on the annealing dynamics of polymer films. We anticipate that systematic studies at shorter annealing times may be informative in revealing the effect of cross-linking degree of the support. We note that the apparent difference in the pattern of terrace formation-bicontinuous pattern on densely cross-linked network (Figure 3d) and holes of the lower terrace in the majority second terrace on loose network (Figure $3 \mathrm{~g}$ ) - is a reflection of a very small $(2-3 \mathrm{~nm}$ ) difference in the film thickness after spin-coating. ${ }^{75}$ For the present discussion, it is important that both swelling network supports facilitate the microdomain ordering on a time scale of $1 \mathrm{~h}$ without altering the morphological behavior as compared to silicon substrates.
UV Ellipsometry Measurements of Individual Layers of Block Copolymer Film and of Network Support. Extending ellipsometry analysis range from vis to UV-vis allows resolving the swelling behavior of the individual layers in the "bilayer systems". To illustrate the principle, Figure 4 is discussed in the following.
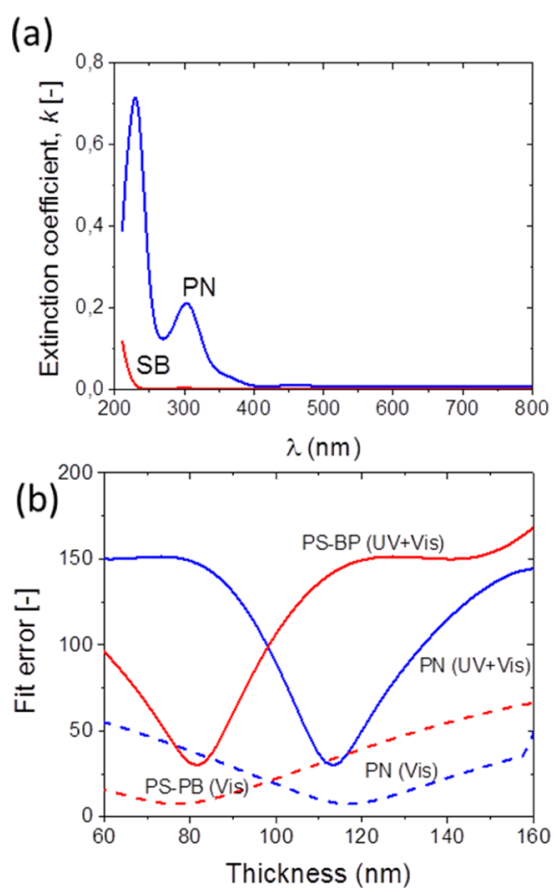

Figure 4. (a) Optical absorption spectra of PN and of PS-b-PB film (PS-PB). (b) Fit parameter versus film thickness uniqueness indicating increased sensitivity (sharper minima) in the UV + vis range $(210-1000 \mathrm{~nm})$ as opposed to the vis range alone $(500-1000$ $\mathrm{nm})$.

The individual PN and PS- $b$-PB films have been measured in a broad range $(210-1000 \mathrm{~nm})$, and the spectra have a very good optical quality with little undesired depolarization and low levels of instrumental noise (Figure S9, Supporting Information). Optical absorption spectra in Figure 4a show that in the visible range, the measured materials are transparent; therefore, the optical contrast that is necessary for the independent resolution is insufficient. In the UV range, however, the network film has absorption peaks around 305 $\mathrm{nm}$ and around $230 \mathrm{~nm}$, whereas PS- $b$-PB does not absorb much down to very low wavelengths. The difference in the UV spectra provides a source of optical contrast, as indicated by the analysis of fit parameter uniqueness in Figure 4b. Fit error is plotted as a function of film thicknesses of each material measured in the full UV + vis range (210-1000 nm) and only in the visible range vis $(500-1000 \mathrm{~nm})$. Modeled Psi spectra of different combinations of thicknesses of PN support and of PS- $b$-PB are shown in Figure S10 (Supporting Information). Clearly, the analysis with the full range results in a much sharper minima, which enhances the sensitivity toward the individual thickness values. In addition, fitting both layers as a single layer with effective optical constants results in a total film thickness of $205.5 \mathrm{~nm}$ and a root-mean-square error (MSE) of the fit of 44 (Figure S11a, Supporting Information). Fitting the system as a bilayer gives a better MSE of 29 and the thicknesses of 113.2 and $81.6 \mathrm{~nm}$ for the network and PS- $b$-PB 
layers, respectively (Figure S11b, Supporting Information). The error bars are $\sim 3 \mathrm{~nm}$ that gives a certainty to detect changes as small as about $3 \mathrm{~nm}(3-4 \%)$ within each layer separately. In the following, we consider the swelling behavior of block copolymer film atop the glassy network support.

Resolving the Swelling Behavior of the PN Support and of the Block Copolymer Film in the Bilayer System. UV-ellipsometric measurements of the swelling of individual layers in "network-PS- $b$-PB" bilayer films have been performed in a quartz cell under temperature-controlled partial vapor pressure, as described in the Experimental Section. The films were first exposed to $37 \% p / p_{0}$ chloroform vapor, and then the vapor concentration was increased up $43 \% p / p_{0}$. We note that at this low-solvent concentration in the film, the PS block is above the glassy state allowing for the structure equilibration. ${ }^{78}$

Figure 5a compares the swelling behavior of PS- $b$-PB films on the silicon substrate (lower curve) and on the PN support,

\section{(a)}
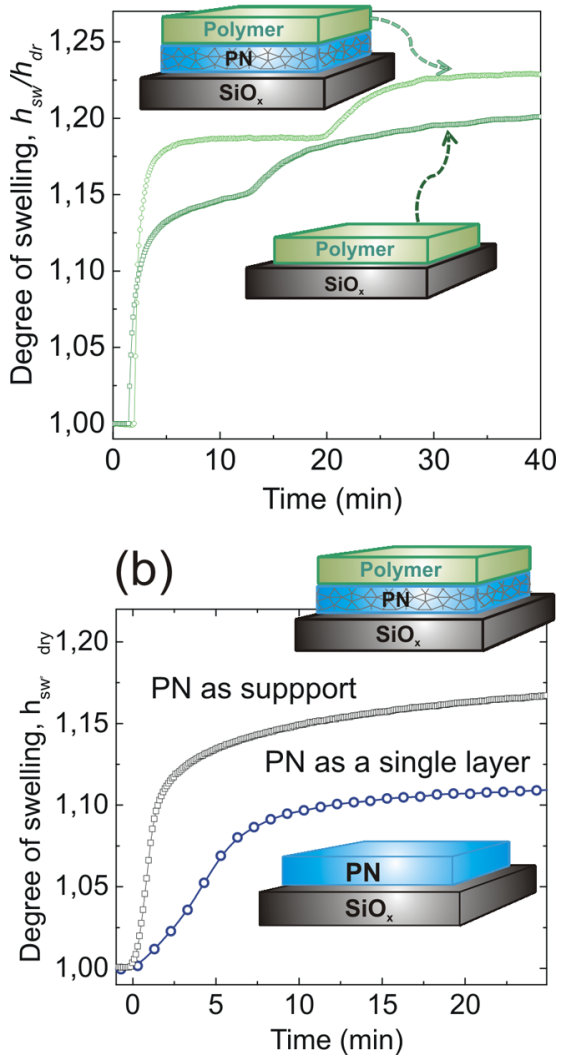

Figure 5. (a) Swelling kinetics of $\sim 90 \mathrm{~nm}$ thick PS-b-PB on silicon substrate (lower curve) and on PN support. After equilibration in a flow of dry nitrogen, the films were initially exposed to vapor tempered to $1{ }^{\circ} \mathrm{C}$, and then the vapor temperature was increased to 4 ${ }^{\circ} \mathrm{C}$, corresponding to $\sim 37$ and $43 \% p / p_{0}$ of chloroform, respectively. (b) Swelling kinetics of densely cross-linked $\mathrm{PN}$ as a single layer (circles, lower curve) and in a bilayer as a support for block copolymer film (triangles) exposed to $\sim 37 \% p / p_{0}$ of the chloroform vapor.

both exposed to the solvent vapor conditions described above. On silicon substrate, the initial swelling rate is markedly retarded after about $1 \mathrm{~min}$ of treatment at $37 \% p / p_{0}$. After 10 $\mathrm{min}$, the swelling degree $\sim 1.14$ is lower as compared to that on PN ( 1.18). Most noticeably, on the network support, the steady-state regime is achieved already after $5 \mathrm{~min}$ of swelling, whereas on silicon wafer, the swelling is still not leveled off after $10 \mathrm{~min}$. When the solvent concentration in the vapors is increased to $43 \% p / p_{0}$, both systems respond with increase in the solvent uptake. The swelling degree at saturation of the PS$b$-PB film in the bilayer is 1.23 , as compared to 1.20 for silicon wafer-supported PS- $b$-PB film. The slightly higher solvent uptake by the SB film in the bilayer at reduced solvent vapor atmosphere is in agreement with our earlier findings on the bilayer film. ${ }^{53}$ The present results convincingly demonstrate that the swelling of the network support beneath the PS- $b$-PB film affects the swelling equilibrium of the block copolymer. At the same time, we note that this small increase in the solvent uptake by PS- $b$-PB films on network support is unlikely to be a decisive reason which provides an increase in the microdomain ordering dynamics (Figure 3).

The swelling behavior of the highly cross-linked PN as a single layer and as a support for the block copolymer film is presented in Figure 5b. The solvent uptake is noticeably enhanced in the presence of the top block copolymer layer so that the swelling is both faster and larger than for a single network layer. The achieved $30 \mathrm{~min}$ degree of swelling of a network-support layer at $37 \% p / p_{0}$ is 1.17 , which is in good agreement with a swelling degree of 1.18 of solvent-treated cross-linked network at $40 \% p / p_{0}$ (Figure 1 ).

Figure 6 compares two swelling measurements of the bilayer films. The data confirm a good reproducibility of the
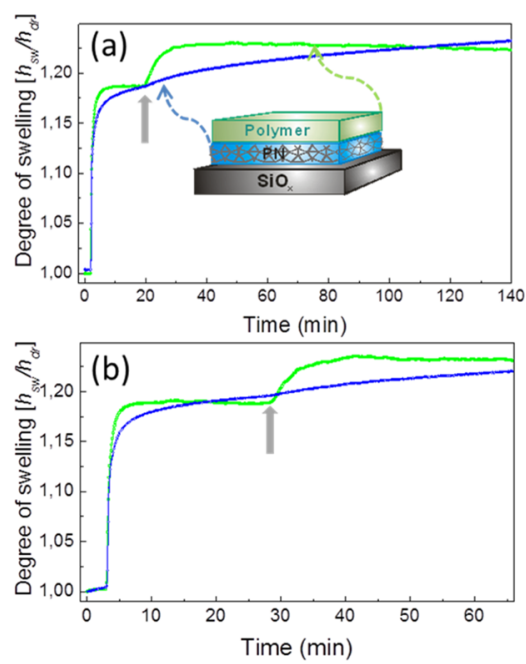

Figure 6. (a) Swelling kinetics resolved with UV-ellipsometry measurements of individual layers in the bilayer system consisting of $\sim 100 \mathrm{~nm}$ thick PN with an intermediate density of cross-linking (II) and of (a) $93 \mathrm{~nm}$ thick and (b) $86 \mathrm{~nm}$ thick PS-b-PB films on top. After equilibration in a flow of dry nitrogen, the films were initially exposed to vapor tempered to $1{ }^{\circ} \mathrm{C}$, and then the vapor temperature was increased to $4{ }^{\circ} \mathrm{C}$ (indicated by gray arrows), corresponding to $\sim 37$ and $43 \% p / p_{0}$ of chloroform, respectively.

environmental conditions in in situ setup because PS- $b$-PB films show identical kinetic and steady-state swelling behavior. The swelling of the PS- $b$-PB layer is clearly sensitive to the change in the atmosphere conditions, as evident by a sharp rise in the swelling curve (Figure $6 \mathrm{a}, \mathrm{b}$ ). In contrast, the swelling behavior of the $\mathrm{PN}$ is continuous without showing a response to the environmental change. This is a clear difference to the environmentally sensitive solvent uptake by the network monolayers shown in Figure $1 \mathrm{a}$, and this change in the 
swelling behavior may be attributed to the presence of the swollen polymer film on top.

Remarkably, at this reduced solvent vapor atmosphere, the bottom network layer swells continuously even when the block copolymer film achieves an equilibrium swelling state, so that at longer equilibration time, the bottom layer swells more than the block copolymer film atop. This is evident from the crossings of the swelling curves at the end of the second swelling step (a) and at the end of the first swelling step (b). A slight decrease in the degree of swelling of PS- $b$-PB layer proceeds presumably on the expenses of the swelling of the network support because cumulative swelling of the bilayer remains steady within hours of annealing. ${ }^{53}$

We believe that continuous swelling and related relaxation of mechanical stresses within the network layer may account for the enhanced segmental dynamics and fast ordering of microdomains even at low-solvent concentration in the film (Figure 3). On a macroscale, a block copolymer film is in its swelling equilibrium, which concerns the overall solvent uptake. On the nanoscale, the defects in the microphaseseparated structure represent excited conformational states. Their annihilation dynamics is directly associated with the segmental mobility. The mechanisms behind the deduced enhanced chain mobility on swollen NP supports have to be explored at shorter time scales, for example, by tracer diffusion methods.

Stability of Polymer Films on Network Supports. Block copolymer films on PN supports showed outstanding stability against dewetting even when the partial vapor pressure of chloroform $p / p_{0}$ was as high as $80 \%$. Under similar conditions, $\sim 50 \mathrm{~nm}$ thick PS- $b$-PB films on silicon substrates typically dewet within less than $10 \mathrm{~min}$. The issue of film stability of solvent-annealed film on network supports was considered for thin films of homopolymers.

Earlier the enhanced stability of thermally annealed PS films on the epoxy layer was attributed to the interpenetration of the chain ends into the meshes of the network. ${ }^{49}$ To address this effect in our system, we have chosen an approach to vary the molecular weight of linear chains to screen the ratio of the chain length/number of chain ends to the mesh size of the PN. We compared thin films of PS homopolymers with molecular weights ranging from short oligomer chains $(5 \mathrm{~kg} / \mathrm{mol})$, well below an entanglement molecular weight of PS of $17 \mathrm{~kg} / \mathrm{mol}$, ${ }^{75}$ to typical block length in block copolymers $(30 \mathrm{~kg} / \mathrm{mol})$ and up to homopolymer with several entanglements per chain in bulk. Because molecular weights strongly affect the viscosity of polymer melts and solutions, for each homopolymer, we have adjusted the film thickness to be able to compare the same time scale of the annealing procedure. Figure 7 displays optical microscopy images of PS films on silicon wafers (left column) and on PNs. All samples have been processed simultaneously under controlled solvent vapor atmosphere. The swelling and film stability on silicon substrate were monitored with in situ ellipsometry (Figure S12, Supporting Information). Annealing at a degree of swelling of 1.25 led to a fast dewetting after 10 min of treatment, as evident from the instability in monitored thickness. Homopolymer films supported by PNs show a much higher stability as compared to similar films on silicon substrates, even in a highly saturated chloroform vapor atmosphere. ${ }^{53}$ We note that detailed analysis of the dewetting patterns as revealed by optical microscopy in Figure 7 is beyond the scope of this study. ${ }^{49,79}$
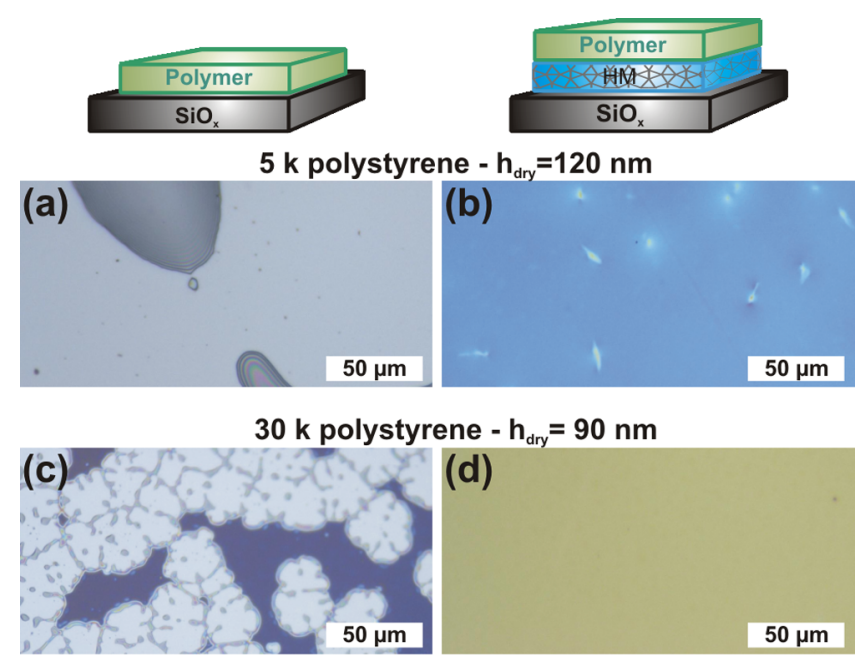

$178 \mathrm{k}$ polystyrene $-\mathrm{h}_{\mathrm{dry}}=35 \mathrm{~nm}$

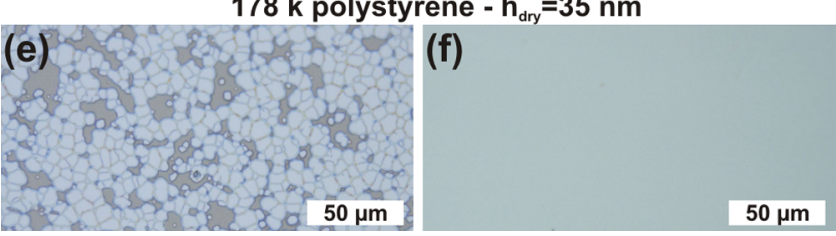

Figure 7. (a-f) Optical microscopy images of PS homopolymer films with molecular weights $(\mathrm{a}, \mathrm{b}) 5 \mathrm{~kg} / \mathrm{mol}\left(h_{\mathrm{dr}} \approx 120 \mathrm{~nm}\right),(\mathrm{c}, \mathrm{d}) 30 \mathrm{~kg} /$ mol $\left(h_{\mathrm{dr}} \approx 90 \mathrm{~nm}\right)$, and $(\mathrm{e}, \mathrm{f}) 178 \mathrm{~kg} / \mathrm{mol}\left(h_{\mathrm{dr}} \approx 35 \mathrm{~nm}\right)$ on silicon substrates $(\mathrm{a}, \mathrm{c}, \mathrm{e})$ and on PN supports $(\mathrm{b}, \mathrm{d}, \mathrm{f})$. All films have been annealed simultaneously under standard conditions for $50 \mathrm{~min}$ in $40 \%$ $p / p_{0}$ and $15 \mathrm{~min}$ in $60 \% p / p_{0}$ of chloroform (Figure S12, Supporting Information).

To exclude a possible contribution of specific interactions of PS chains with aromatic network material, we performed similar annealing tests with benzene-free homopolymer compositions. Figure S13 (Supporting Information) compares $\sim 50 \mathrm{~nm}$ thick films of PMMA homopolymer on silicon wafers and PN supports after treatment in a controlled chloroform vapor atmosphere and confirms a suppression of dewetting by network supports irrespective of the homopolymer composition.

We believe that the network layer prevents an accumulation of excess solvent film at the polymer-network-support interface and provides interdigitation of the chain ends with the network structure, both factors leading to effectively stronger interactions between the layers. Additionally, high wetting hysteresis on PN supports (Figure S5, Supporting Information) may also account for a higher stability of films of linear polymers toward dewetting, as compared to that on conventional silicon substrates. ${ }^{53}$ It is remarkable that organic PN supports provide two opposing kinetic effects: enhanced segmental dynamics and strongly retarded dewetting of polymer chains under solvent vapor processing.

\section{SUMMARY AND CONCLUSIONS}

We employed "interactive" densely cross-linked networks as supports for solvent-vapor processing of thin polymer films. Sub-100 nm thick surface-attached PNs on silicon wafers exhibit environmentally sensitive glasslike swelling behavior. The relaxation-driven equilibration of the $\mathrm{PN}$ is shown to be dependent on the pretreatment of the thermally cured network in organic solvent, as well as on the degree of the cross-linked density. The information on swelling modes of the individual 
PN layer has been used to evaluate the interaction of the swollen PN support with a block copolymer film atop during solvent vapor annealing. Comparative solvent annealing experiments have been performed under controlled temperature and vapor flow, assuring highly reproducible and stable environmental conditions.

We have shown that the individual properties of two contacting polymeric materials, that is, slow swelling and irreversible deswelling behavior of glassy networks on one hand and fast solvent uptake to steady-state swelling of linear polymer chains on the other hand, exhibit a mutual influence on the segmental dynamics and relaxation of the conformational states. In particular, the PN layer below a polymer film exhibits significantly faster swelling and a higher solvent uptake, as compared to a single PN layer on silicon substrate. At the same time, block copolymer films on PN supports exhibit faster ordering dynamics and exceptional stability toward dewetting as compared to similar films on silicon wafers. Also, homopolymer films on PN supports demonstrate high stability for a wide range of molecular weights and different chemical compositions.

Moreover, the swelling of PNs is a continuous long-term process even when the polymer film on top reaches a steadystate swelling. This observation suggests that the mechanical stress produced by continuously swelling PN and solvent transport through the block copolymer film account for the enhanced segmental dynamics even at low-solvent concentration in the block copolymer film. Here, the reported findings might be relevant, for example, for controlling the crystallization behavior of semicrystalline polymers on the expenses of the amorphous parts by exposure to the reduced solvent vapor. In particular, this strategy can be pursued to increase the crystallinity of conjugated polymers to improve the long-range charge transport and therefore the efficiency of organic electronic devices. Another broad application area related to the increasing technological importance of confined polymer materials, such as film, fibers, and membranes, is the possibility of fast annealing leading to predefined processing molecular conformations and potentially to novel properties. ${ }^{80}$ Furthermore, established in this work is the successful application of UV ellipsometry for advanced characterization of complex polymer films that can be used to extend the knowledge on the solvent uptake by other confined systems.

\section{ASSOCIATED CONTENT}

\section{(S) Supporting Information}

The Supporting Information is available free of charge on the ACS Publications website at DOI: 10.1021/acs.langmuir.8b02304.

Calculations of the partial vapor pressure $p / p_{0}$ of chloroform; evaluation of the $T_{\mathrm{g}}$, thermal stability and light adsorption extinction coefficient of $\mathrm{PN}$; kinetics of swelling-deswelling of $\mathrm{PN}$ films with a varied degree of cross-linking; SFM images of PN films upon different treatment procedures; contact angle values and evaluated surface energy of PN films; SFM images of as-spin coated and of solvent annealedPS- $b$-PB films; examples of measured and modeled multianglespectra of polymer network and of PS- $b$-PB film, as well as of the bilayer; swelling regime in stability tests; and optical microscopy images of PMMA homopolymer films annealed on silicon and on PN substrates (PDF)

\section{AUTHOR INFORMATION}

\section{Corresponding Author}

*E-mail: tsarkova@colloid.chem.msu.ru.

ORCID

Nieck Benes: 0000-0001-9716-069X

Larisa A. Tsarkova: 0000-0002-8615-2886

Present Addresses

${ }^{\perp}$ Advanced Membranes \& Porous Materials Center, King Abdullah University of Science and Technology, Thuwal, Saudi Arabia.

\#Institute of Building Materials Research, RWTH Aachen University, Schinkelstraße 3, 52062 Aachen, Germany.

\section{Author Contributions}

W.O. and A.S.-F. contributed equally. All authors have given approval to the final version of the manuscript.

\section{Notes}

The authors declare no competing financial interest.

\section{ACKNOWLEDGMENTS}

L.A.T. and Y.B. acknowledge the financial support by the Russian Foundation for Basic Research (RFBR) according to the research project no. 18-53-76005 in the framework of the ERA.Net Plus Project JetVA.

\section{REFERENCES}

(1) Hamley, I. W. The Physics of Block Copolymers; Oxford University Press: Oxford, 1998.

(2) Alcoutlabi, M.; McKenna, G. B. Effects of confinement on material behaviour at the nanometre size scale. J. Phys.: Condens. Matter 2005, 17, R461-R524.

(3) Reiter, G.; Napolitano, S. Possible Origin of ThicknessDependent Deviations from Bulk Properties of Thin Polymer Films. J. Polym. Sci., Part B: Polym. Phys. 2010, 48, 2544-2547.

(4) Napolitano, S.; Wübbenhorst, M. The lifetime of the deviations from bulk behaviour in polymers confined at the nanoscale. Nat. Commun. 2011, 2, 260.

(5) Vogt, B. D.; Soles, C. L.; Jones, R. L.; Wang, C.-Y.; Lin, E. K.; Wu, W.-1.; Satija, S. K.; Goldfarb, D. L.; Angelopoulos, M. Interfacial Effects on Moisture Absorption in Thin Polymer Films. Langmuir 2004, 20, 5285-5290.

(6) Tress, M.; Erber, M.; Mapesa, E. U.; Huth, H.; Müller, J.; Serghei, A.; Schick, C.; Eichhorn, K.-J.; Voit, B.; Kremer, F. Glassy Dynamics and Glass Transition in Nanometric Thin Layers of Polystyrene. Macromolecules 2010, 43, 9937-9944.

(7) Tsuruta, H.; Fujii, Y.; Kai, N.; Kataoka, H.; Ishizone, T.; Doi, M.; Morita, H.; Tanaka, K. Local Conformation and Relaxation of Polystyrene at Substrate Interface. Macromolecules 2012, 45, 46434649.

(8) Inutsuka, M.; Horinouchi, A.; Tanaka, K. Aggregation States of Polymers at Hydrophobic and Hydrophilic Solid Interfaces. ACS Macro Lett. 2015, 4, 1174-1178.

(9) Thompson, R. L.; McDonald, M. T.; Lenthall, J. T.; Hutchings, L. R. Solvent Accelerated Polymer Diffusion in Thin Films. Macromolecules 2005, 38, 4339-4344.

(10) Thomas, K. R.; Chenneviere, A.; Reiter, G.; Steiner, U. Nonequilibrium behavior of thin polymer films. Phys. Rev. E: Stat., Nonlinear, Soft Matter Phys. 2011, 83, 021804.

(11) Barbero, D. R.; Steiner, U. Nonequilibrium Polymer Rheology in Spin-Cast Films. Phys. Rev. Lett. 2009, 102, 248303.

(12) Mukherjee, M.; Bhattacharya, M.; Sanyal, M. K.; Geue, T.; Grenzer, J.; Pietsch, U. Reversible negative thermal expansion of polymer films. Phys. Rev. E: Stat., Nonlinear, Soft Matter Phys. 2002, 66, 061801.

(13) Ogieglo, W.; de Grooth, J.; Wormeester, H.; Wessling, M.; Nijmeijer, K.; Benes, N. E. Relaxation induced optical anisotropy 
during dynamic overshoot swelling of zwitterionic polymer films. Thin Solid Films 2013, 545, 320-326.

(14) Zettl, U.; Knoll, A.; Tsarkova, L. Effect of Confinement on the Mesoscale and Macroscopic Swelling of Thin Block Copolymer Films. Langmuir 2010, 26, 6610-6617.

(15) Ogieglo, W.; Wormeester, H.; Wessling, M.; Benes, N. E. Probing the Surface Swelling in Ultra-Thin Supported Polystyrene Films During Case II Diffusion of n-Hexane. Macromol. Chem. Phys. 2013, 214, 2480-2488.

(16) Ogieglo, W.; Rahimi, K.; Rauer, S. B.; Ghanem, B.; Ma, X.; Pinnau, I.; Wessling, M. How Do Organic Vapors Swell Ultrathin Films of Polymer of Intrinsic Microporosity PIM-1? J. Phys. Chem. B 2017, 121, 7210-7220.

(17) Oikonomou, P.; Botsialas, A.; Manoli, K.; Goustouridis, D.; Valamontes, E.; Sanopoulou, M.; Raptis, I.; Patsis, G. P. Chemocapacitor performance modeling by means of polymer swelling optical measurements. Sens. Actuators, B 2012, 171-172, 409-415.

(18) Spaeth, K.; Gauglitz, G. Characterisation of the optical properties of thin polymer films for their application in detection of volatile organic compounds. Mater. Sci. Eng., C 1998, 5, 187-191.

(19) Verploegen, E.; Sokolov, A. N.; Akgun, B.; Satija, S. K.; Wei, P.; Kim, D.; Kapelewski, M. T.; Bao, Z.; Toney, M. F. Swelling of Polymer Dielectric Thin Films for Organic-Transistor-Based Aqueous Sensing Applications. Chem. Mater. 2013, 25, 5018-5022.

(20) Ogieglo, W.; Ghanem, B.; Ma, X.; Pinnau, I.; Wessling, M. How Much Do Ultrathin Polymers with Intrinsic Microporosity Swell in Liquids? J. Phys. Chem. B 2016, 120, 10403-10410.

(21) Hild, G. Interpretation of equilibrium swelling data on model networks using affine and "phantom" network models. Polymer 1997, 38, 3279-3293.

(22) Ogieglo, W.; Wormeester, H.; Eichhorn, K.-J.; Wessling, M.; Benes, N. E. In situ ellipsometry studies on swelling of thin polymer films: A review. Prog. Polym. Sci. 2015, 42, 42-78.

(23) Ogieglo, W.; van der Werf, H.; Tempelman, K.; Wormeester, H.; Wessling, M.; Nijmeijer, A.; Benes, N. E. n-Hexane induced swelling of thin PDMS films under non-equilibrium nanofiltration permeation conditions, resolved by spectroscopic ellipsometry. J. Membr. Sci. 2013, 431, 233-243.

(24) Dušek, K.; Dušková-Smrčková, M.; Douglas, C. B. Swelling of Coating Films. In Protective Coatings: Film Formation and Properties; Wen, M., Dušek, K., Eds.; Springer International Publishing: Cham, 2017; pp 271-291.

(25) Manoli, K.; Goustouridis, D.; Chatzandroulis, S.; Raptis, I.; Valamontes, E. S.; Sanopoulou, M. Vapor sorption in thin supported polymer films studied by white light interferometry. Polymer 2006, 47, 6117-6122.

(26) Manoli, K.; Goustouridis, D.; Raptis, I.; Valamontes, E.; Sanopoulou, M. Vapor-Induced Swelling of Supported Methacrylic and Siloxane Polymer Films: Determination of Interaction Parameters. J. Appl. Polym. Sci. 2010, 116, 184-190.

(27) Shibayama, M.; Shirotani, Y.; Hirose, H.; Nomura, S. Simple Scaling Rules on Swollen and Shrunken Polymer Gels. Macromolecules 1997, 30, 7307-7312.

(28) Canal, T.; Peppas, N. A. Correlation between Mesh Size and Equilibrium Degree of Swelling of Polymeric Networks. J. Biomed. Mater. Res. 1989, 23, 1183-1193.

(29) Tokarev, I.; Minko, S. Stimuli-responsive hydrogel thin films. Soft Matter 2009, 5, 511-524.

(30) Biesalski, M.; Rühe, J. Scaling Laws for the Swelling of Neutral and Charged Polymer Brushes in Good Solvents. Macromolecules 2002, 35, 499-507.

(31) Habicht, J.; Schmidt, M.; Rühe, J.; Johannsmann, D. Swelling of Thick Polymer Brushes Investigated with Ellipsometry. Langmuir 1999, 15, 2460-2465.

(32) Karim, A.; Satija, S. K.; Douglas, J. F.; Ankner, J. F.; Fetters, L. J. Neutron reflectivity study of the density profile of a model endgrafted polymer brush: influence of solvent quality. Phys. Rev. Lett. 1994, 73, 3407-3410.
(33) Noro, A.; Tomita, Y.; Matsushita, Y.; Thomas, E. L. EnthalpyDriven Swelling of Photonic Block Polymer Films. Macromolecules 2016, 49, 8971-8979.

(34) Peters, R. D.; Dalnoki-Veress, K. Film thickness dependent ordering dynamics of lamellar forming diblock copolymer thin films. Eur. Phys. J. E: Soft Matter Biol. Phys. 2012, 35, 132.

(35) Posselt, D.; Zhang, J.; Smilgies, D.-M.; Berezkin, A. V.; Potemkin, I. I.; Papadakis, C. M. Restructuring in block copolymer thin films: In situ GISAXS investigations during solvent vapor annealing. Prog. Polym. Sci. 2017, 66, 80-115.

(36) Hild, G. Model networks based on "endlinking" processes: synthesis, structure and properties. Prog. Polym. Sci. 1998, 23, 10191149.

(37) Dušek, K.; Choukourov, A.; Dušková-Smrčková, M.; Biederman, H. Constrained Swelling of Polymer Networks: Characterization of Vapor-Deposited Cross-Linked Polymer Thin Films. Macromolecules 2014, 47, 4417-4427.

(38) Saalwächter, K.; Chassé, W.; Sommer, J.-U. Structure and swelling of polymer networks: insights from NMR. Soft Matter 2013, 9, 6587-6593.

(39) Sinturel, C.; Vayer, M.; Morris, M.; Hillmyer, M. A. Solvent Vapor Annealing of Block Polymer Thin Films. Macromolecules 2013, 46, 5399-5415.

(40) Luo, M.; Epps, T. H. Directed Block Copolymer Thin Film Self-Assembly: Emerging Trends in Nanopattern Fabrication. Macromolecules 2013, 46, 7567-7579.

(41) Xu, Y.-X.; Chueh, C.-C.; Yip, H.-L.; Ding, F.-Z.; Li, Y.-X.; Li, C.-Z.; Li, X.; Chen, W.-C.; Jen, A. K.-Y. Improved Charge Transport and Absorption Coefficient in Indacenodithieno[3,2-b]thiophenebased Ladder-Type Polymer Leading to Highly Efficient Polymer Solar Cells. Adv. Mater. 2012, 24, 6356-6361.

(42) Verploegen, E.; Miller, C. E.; Schmidt, K.; Bao, Z.; Toney, M. F. Manipulating the Morphology of P3HT-PCBM Bulk Heterojunction Blends with Solvent Vapor Annealing. Chem. Mater. 2012, 24, 3923-3931.

(43) Xiong, Z.; Liu, C. Optimization of inkjet printed PEDOT:PSS thin films through annealing processes. Org. Electron. 2012, 13, 15321540.

(44) Barnes, K. A.; Karim, A.; Douglas, J. F.; Nakatani, A. I.; Gruell, H.; Amis, E. J. Suppression of dewetting in nanoparticle-filled polymer films. Macromolecules 2000, 33, 4177-4185.

(45) Chen, P.; Liang, H. Monte Carlo Simulations of CylinderForming ABC Triblock Terpolymer Thin Films. J. Phys. Chem. B 2006, 110, 18212-18224.

(46) Krishnan, R. S.; Mackay, M. E.; Duxbury, P. M.; Hawker, C. J.; Asokan, S.; Wong, M. S.; Goyette, R.; Thiyagarajan, P. Improved polymer thin-film wetting behavior through nanoparticle segregation to interfaces. J. Phys.: Condens. Matter 2007, 19, 356003.

(47) Xue, L.; Han, Y. Inhibition of dewetting of thin polymer films. Prog. Mater. Sci. 2012, 57, 947-979.

(48) Carroll, G. T.; Sojka, M. E.; Lei, X.; Turro, N. J.; Koberstein, J. T. Photoactive additives for cross-linking polymer films: Inhibition of dewetting in thin polymer films. Langmuir 2006, 22, 7748-7754.

(49) Jeon, H. S.; Dixit, P. S.; Yim, H. Dewetting of thin polystyrene films absorbed on epoxy coated substrates. J. Chem. Phys. 2005, 122, 104707.

(50) Mackay, M. E.; Hong, Y.; Jeong, M.; Hong, S.; Russell, T. P.; Hawker, C. J.; Vestberg, R.; Douglas, J. F. Influence of dendrimer additives on the dewetting of thin polystyrene films. Langmuir 2002, $18,1877-1882$

(51) Xu, L.; Yu, X.; Shi, T.; An, L. Investigation of the dewetting inhibition mechanism of thin polymer films. Soft Matter 2009, 5, 2109-2116.

(52) Yerushalmi-Rozen, R.; Klein, J.; Fetters, L. J. Suppression of Rupture in Thin, Nonwetting Liquid Films. Science 1994, 263, 793795.

(53) Stenbock-Fermor, A.; Knoll, A. W.; Böker, A.; Tsarkova, L. Enhancing Ordering Dynamics in Solvent-Annealed Block Copolymer 
Films by Lithographic Hard Mask Supports. Macromolecules 2014, 47, 3059-3067.

(54) Cheong, L. L.; Paul, P.; Holzner, F.; Despont, M.; Coady, D. J.; Hedrick, J. L.; Allen, R.; Knoll, A. W.; Duerig, U. Thermal Probe Maskless Lithography for $27.5 \mathrm{~nm}$ Half-Pitch Si Technology. Nano Lett. 2013, 13, 4485-4491.

(55) Jeong, J. W.; Hur, Y. H.; Kim, H.-j.; Kim, J. M.; Park, W. I.; Kim, M. J.; Kim, B. J.; Jung, Y. S. Proximity Injection of Plasticizing Molecules to Self-Assembling Polymers for Large-Area, Ultrafast Nanopatterning in the Sub-10-nm Regime. ACS Nano 2013, 7, 67476757.

(56) Shelton, C. K.; Jones, R. L.; Epps, T. H. Kinetics of Domain Alignment in Block Polymer Thin Films during Solvent Vapor Annealing with Soft Shear: An in Situ Small-Angle Neutron Scattering Investigation. Macromolecules 2017, 50, 5367-5376.

(57) Qiang, Z.; Zhang, L.; Stein, G. E.; Cavicchi, K. A.; Vogt, B. D. Unidirectional Alignment of Block Copolymer Films Induced by Expansion of a Permeable Elastomer during Solvent Vapor Annealing. Macromolecules 2014, 47, 1109-1116.

(58) Luo, M.; Scott, D. M.; Epps, T. H. Writing Highly Ordered Macroscopic Patterns in Cylindrical Block Polymer Thin Films via Raster Solvent Vapor Annealing and Soft Shear. ACS Macro Lett. 2015, 4, 516-520.

(59) Seguini, G.; Zanenga, F.; Giammaria, T. J.; Ceresoli, M.; Sparnacci, K.; Antonioli, D.; Gianotti, V.; Laus, M.; Perego, M. Enhanced Lateral Ordering in Cylinder Forming PS-b-PMMA Block Copolymers Exploiting the Entrapped Solvent. ACS Appl. Mater. Interfaces 2016, 8, 8280-8288.

(60) Elbs, H.; Krausch, G. Ellipsometric determination of FloryHuggins interaction parameters in solution. Polymer 2004, 45, 79357942.

(61) Knoll, A.; Magerle, R.; Krausch, G. Phase behavior in thin films of cylinder-forming ABA block copolymers: Experiments. J. Chem. Phys. 2004, 120, 1105-1116.

(62) Gensel, J.; Liedel, C.; Schoberth, H. G.; Tsarkova, L. Microstructure-macro-response relationship in swollen block copolymer films. Soft Matter 2009, 5, 2534-2537.

(63) Tsarkova, L.; Knoll, A.; Krausch, G.; Magerle, R. SubstrateInduced Phase Transitions in Thin Films of Cylinder-Forming Diblock Copolymer Melts. Macromolecules 2006, 39, 3608-3615.

(64) Shelton, C. K.; Jones, R. L.; Dura, J. A.; Epps, T. H. Tracking Solvent Distribution in Block Polymer Thin Films during Solvent Vapor Annealing with in Situ Neutron Scattering. Macromolecules 2016, 49, 7525-7534.

(65) Owens, D. K.; Wendt, R. C. Estimation of the surface free energy of polymers. J. Appl. Polym. Sci. 1969, 13, 1741-1747.

(66) Zhang, X.; Yager, K. G.; Kang, S.; Fredin, N. J.; Akgun, B.; Satija, S.; Douglas, J. F.; Karim, A.; Jones, R. L. Solvent Retention in Thin Spin-Coated Polystyrene and Poly(methyl methacrylate) Homopolymer Films Studied By Neutron Reflectometry. Macromolecules 2010, 43, 1117-1123.

(67) Paul, D. R. Dual Mode Sorption Model. In Encyclopedia of Membranes; Drioli, E., Giorno, L., Eds.; Springer Berlin Heidelberg: Berlin, Heidelberg, 2016; pp 1-2.

(68) von Schroeder, P. Uber Erstarrungs- und Quellugserscheinungen von Gelatine. Z. Phys. Chem. 1903, 45U, 75.

(69) Davankov, V. A.; Pastukhov, A. V. Paradoxes of Thermodynamics of Swelling Equilibria of Polymers in Liquids and Vapors. J. Phys. Chem. B 2011, 115, 15188-15195.

(70) Berens, A. R.; Hopfenberg, H. B. Diffusion and relaxation in glassy polymer powders: 2 . Separation of diffusion and relaxation parameters. Polymer 1978, 19, 489-496.

(71) Coulon, G.; Ausserre, D.; Russell, T. P. Interference microscopy on thin diblock copolymer films. J. Phys. 1990, 51, $777-786$.

(72) Coulon, G.; Collin, B.; Ausserre, D.; Chatenay, D.; Russell, T. $P$. Islands and holes on the free surface of thin diblock copolymer films. I. Characteristics of formation and growth. J. Phys. 1990, 51, 2801-2811.
(73) Maher, M. J.; Self, J. L.; Stasiak, P.; Blachut, G.; Ellison, C. J.; Matsen, M. W.; Bates, C. M.; Willson, C. G. Structure, Stability, and Reorganization of 0.5 L0 Topography in Block Copolymer Thin Films. ACS Nano 2016, 10, 10152-10160.

(74) Shelton, C. K.; Epps, T. H. Mapping Substrate Surface Field Propagation in Block Polymer Thin Films. Macromolecules 2016, 49, 574-580.

(75) Tsarkova, L. Distortion of a Unit Cell versus Phase Transition to Nonbulk Morphology in Frustrated Films of Cylinder-Forming Polystyrene-b-polybutadiene Diblock Copolymers. Macromolecules 2012, 45, 7985-7994.

(76) Horvat, A.; Sevink, G. J. A.; Zvelindovsky, A. V.; Krekhov, A.; Tsarkova, L. Specific Features of Defect Structure and Dynamics in the Cylinder Phase of Block Copolymers. ACS Nano 2008, 2, 11431152.

(77) Tsarkova, L. Structure and Dynamics of Cylinder forming Block Copolymers in Thin Films. In Nanostructured Soft Matter: Experiment, Theory, Simulation and Perspectives; Zvelindovsky, A. V., Ed.; Springer: Heidelberg, 2007; pp 231-266.

(78) Stenbock-Fermor, A.; Rudov, A. A.; Gumerov, R. A.; Tsarkova, L. A.; Böker, A.; Möller, M.; Potemkin, I. I. Morphology-Controlled Kinetics of Solvent Uptake by Block Copolymer Films in Nonselective Solvent Vapors. ACS Macro Lett. 2014, 3, 803-807.

(79) Milchev, A.; Binder, K. Dewetting of thin polymer films adsorbed on solid substrates: A Monte Carlo simulation of the early stages. J. Chem. Phys. 1997, 106, 1978-1989.

(80) Chandran, S.; Handa, R.; Kchaou, M.; Al Akhrass, S.; Semenov, A. N.; Reiter, G. Time Allowed for Equilibration Quantifies the Preparation Induced Nonequilibrium Behavior of Polymer Films. ACS Macro Lett. 2017, 6, 1296-1300. 